\title{
Clinical Study Health Care Seeking Behavior among Caregivers of Sick Children Who Had Cerebral Malaria in Northwestern Nigeria
}

\author{
Edwin E. Eseigbe, ${ }^{1}$ Jane O. Anyiam, ${ }^{1}$ Gboye O. Ogunrinde, ${ }^{1}$ \\ Robinson D. Wammanda, ${ }^{1}$ and Hassan A. Zoaka ${ }^{1,2}$ \\ ${ }^{1}$ Department of Paediatrics, Ahmadu Bello University Teaching Hospital (ABUTH), Zaria 810006, Nigeria \\ ${ }^{2}$ Child Development Centre, Cannock Chase Hospital, Staffordshire, Cannock, UK
}

Correspondence should be addressed to Edwin E. Eseigbe, eeeseigbe@yahoo.com

Received 26 October 2011; Revised 23 December 2011; Accepted 4 January 2012

Academic Editor: Polrat Wilairatana

Copyright ( 2012 Edwin E. Eseigbe et al. This is an open access article distributed under the Creative Commons Attribution License, which permits unrestricted use, distribution, and reproduction in any medium, provided the original work is properly cited.

\begin{abstract}
Cerebral malaria is a significant cause of childhood morbidity in our region. The challenges of effective management include time and quality of treatment. The study appraised the health care seeking behavior of caregivers of sick children who developed cerebral malaria, in Zaria, northwestern Nigeria. Caregivers indentified were parents 29 (87.9\%) and grandparents 4 (12.1\%). Most of them were in the upper social classes. Health care options utilized before presentation at our facility were formal health facility $24(72.7 \%)$, patent medicine seller $12(36.4 \%)$, home treatment $10(30.3 \%)$, and herbal concoction $6(18.2 \%)$ with majority 24 (72.7\%) using more than one option. Antimalarial therapy was instituted in 25 (75.6\%) of the cases. Mortality was significantly associated with the use of herbal concoction, treatment at a formal health facility and patent medicine seller, multiple convulsions, age less than 5 years, and noninstitution of antimalarial therapy before presentation. The study showed use of inappropriate health care options by caregivers and highlighted the need to pursue an awareness drive among caregivers on the use of health care options.
\end{abstract}

\section{Introduction}

Cerebral malaria, a severe form of malaria caused by Plasmodium falciparum, is a significant cause of childhood morbidity and mortality in sub-Saharan Africa [1-3]. It accounts for $1 \%$ to $27 \%$ of paediatric admissions with case fatality rates ranging from $15 \%$ to $50 \%$ in our region [3]. Outcome of the disease is influenced by age of child, severity of symptoms, time of intervention and, quality of treatment received $[2,3]$. Naturally caregivers of children play a pivotal role in the provision of care for childhood diseases. Since most children cannot fend for themselves, time of intervention and quality of care received depend on the actions of the caregiver. Understanding the concept and consequences of disease, knowledge of treatment modalities, and the capacity to provide or access care are some of the factors that could influence the health care seeking behavior of caregivers.
Thus, appraising caregiver health care seeking behavior is necessary for effective prevention and control of grave childhood diseases such as cerebral malaria.

This study was undertaken to examine the health care seeking behavior of caregivers of sick children who presented with cerebral malaria at Ahmadu Bello University Teaching Hospital (ABUTH), Zaria and the impact, if any, on the outcome of the disease.

\section{Materials and Methods}

The study was carried out, with approval of the ABUTH ethical and research committee, in the Department of Paediatrics, ABUTH, Zaria, situated in northwestern Nigeria. All received standard treatment for cerebral malaria in accordance with WHO recommendations [3]. It involved a review of thirty three cases of cerebral malaria managed between January 2000 and December 2009. Parameters reviewed were 
the children's clinical features, the caregiver's social class distribution using Oyedeji's [4] social class classification and health care options utilized by them, duration of symptoms before presentation at ABUTH, and outcome of the disease. Terms used in the study were defined thus as the following.

2.1. Inclusion Criteria. Presence of asexual forms of Plasmodium falciparum, coma with or without seizures, and absence of other identifiable cause of fever or coma. Those with severe parasitaemia ( $>250,000$ parasites/uL of blood), coma, and whose cerebrospinal fluid culture yielded no bacterial isolates were also included. The Glasgow Coma Score (GCS) was used in assessing coma.

2.2. Caregiver. An individual whose responsibility, at a given time, is the care of a child.

2.3. Home Treatment. Administration of drugs at home without prescription.

2.4. Herbal Concoction. Use of herbal mixtures topically or orally.

2.5. Patient Medicine Seller (PMS) [5]. Individual licensed to sell and dispense limited number of drugs such as over the counter drugs.

2.6. Formal Health Facility. Primary health care centre, private or government hospital offering health care at a lower level than ABUTH.

2.7. Social Class. The classification by Oyedeji was further grouped as Upper Social Class (I-III) and Lower Social Class (IV and V).

\subsection{The Unit. Department of Paediatrics, ABUTH, Zaria.}

2.9. Sample Size. Determination of sample size was dependent on the case definition which can be tenuous in cerebral malaria particularly with regards to the challenge of excluding all other possible causes of coma in a resource poor setting like ours. The last study carried out in Zaria reviewed 50 cases over a period of seven years [2]. Only 33 cases were reviewed in this study despite including all those who had severe parasitaemia and coma. In addition the increase in the number of tertiary health care institutions in the region over the years could have resulted in a reduction of those presenting to the unit.

2.10. Data Analysis. The variables were analyzed using frequencies, statistical averages, and standard deviation for variability. Test for significance was carried out using Chi-square with Fisher's exact test, and $P$ values $<0.05$ were regarded as statistically significant.
TABLe 1: Presenting features in 33 children with cerebral malaria.

\begin{tabular}{lcc}
\hline Presenting features & No. of children & Percent of total \\
\hline Fever & 33 & 100 \\
Coma & 33 & 100 \\
Convulsion & 29 & 87.9 \\
Headache & 19 & 57.6 \\
Abdominal pain & 10 & 30.3 \\
\hline
\end{tabular}

\section{Results}

3.1. Clinical Features of the Patients. A total of 33 cases were reviewed, 24 were males and 9 females $(\mathrm{M}: \mathrm{F}, 2.7: 1)$. The age range was 0.75 to 11 years (mean $3.0 \pm 1.1$ years), and $12(36.4 \%)$ were under fives. The presenting features are as shown in Table 1 with fever and coma occurring in all the patients.

3.2. Characteristics of Caregivers. Parents and grandparents were primarily responsible for care in $29(87.9 \%)$ and 4 $(12.1 \%)$ of the cases, respectively.

The Social class distribution of the caregivers was: I 2 (6.1\%), II 3 (9.1\%), III 15 (45.4\%), IV 11 (33.3\%), and V $2(6.1 \%)$. Thus, $20(60.6 \%)$ were in the upper social class, while $13(39.4 \%)$ made up the lower social class. There were 4 cases of mortality associated with the lower class and 1 in the upper class. However, this association was not significant $(P=0.07)$.

3.3. Health Care Options. Of the 33 cases, 24 (72.7\%) utilized more than one option before eventual presentation at the unit (Table 2). There was administration of antimalarial therapy in $25(75.8 \%)$ of the cases.

(a) PMS: This was the commonest $12(36.4 \%)$ health care option used as first choice (Table 2). All received an oral antimalarial (chloroquine, quinine, or artesunate) and either oral acetaminophen or ibuprofen. $7(58.3 \%)$ received an oral antibiotic (chloramphenicol or metronidazole) for presumed typhoid fever. This option was associated with a case of mortality.

(b) Home Treatment: All received oral acetaminophen for fever, while $4(40 \%)$ were given an oral antimalarial drug (chloroquine or a sulphadoxine/pyrimethamine combination). No mortality was associated with this option.

(c) Health Facility: Similarly, all who used this option received either an oral or a parenteral antimalarial drug. In addition, 22 (91.7\%) received antibiotics. A case of mortality was associated with this health care option.

(d) Herbal Concoction: 6 (18.2\%) of the cases used this option. Its use was associated with 3 cases of mortality.

4 cases of mortality occurred among the 8 cases that did not receive any antimalarial therapy before presentation at 
TABLE 2: Distribution of health care option utilization among caregivers of 33 children with cerebral malaria.

\begin{tabular}{lcccccc}
\hline \multirow{2}{*}{ Health care option } & \multicolumn{3}{c}{ No. per choice of health care option } & \multicolumn{2}{c}{ Total no. per health care option } \\
\hline Health facility & 1 st & 2nd & 3rd & 4th & 24 & 72.7 \\
PMS & 9 & 13 & 2 & 0 & 12 & 36.4 \\
Home treatment & 12 & 0 & 0 & 0 & 10 & 3 \\
Herbal concoction & 10 & 0 & 0 & 0 & 33 & 18.2 \\
The unit & 2 & 4 & 0 & 0 & 2 & 100.0 \\
\hline
\end{tabular}

TABLe 3: Presenting features associated with mortality in 33 children with cerebral malaria.

\begin{tabular}{lcccc}
\hline Presenting features & Total & Survived & Died & $P$ Value \\
\hline All patients & 33 & 28 & 5 & \\
Age $<5$ years & 12 & 8 & 4 & 0.047 \\
Multiple convulsions & 17 & 12 & 5 & 0.044 \\
Prolonged coma & 8 & 3 & 5 & 0.002 \\
Severe anemia & 8 & 3 & 5 & 0.002 \\
Low GCS $(<5)$ & 14 & 12 & 2 & 1.00 \\
\hline
\end{tabular}

the unit, while only one was associated with the 25 who had. The occurrence of mortality among those who did not receive any antimalarial drug was significant $(P=0.008)$.

3.4. Time of Presentation at the Unit. Day of presentation at the unit in relation to onset of symptoms was: $3,5,11,6$, and 8 cases on days $1,2,3,4$, and 5, respectively. Most 25 $(75.8 \%)$ presented at the unit more than 2 days after onset of symptoms. None utilized the unit as first choice health care option, while $9(27 \%), 22(67 \%)$, and 2 (6\%) utilized the facility as second, third, and fourth option, respectively. The least distance of the abode of any of the caregivers from the unit was about 3 kilometers.

3.5. Outcome at the Unit. There were 5 (15.2\%) cases of mortality (Tables 3 and 4) which were significantly associated with the use of herbal concoction, treatment at a formal health facility, prolonged coma, severe anemia, multiple convulsions, and age less than 5 years. All the deaths occurred among those who presented at the unit 2 days after onset of symptoms. All survivors recovered without any sequelae.

\section{Discussion}

This study showed the use of health care options by caregivers of sick children who developed cerebral malaria. Generally, their initial options were inappropriate, and there was delay in presentation at the unit.

Majority $(60.6 \%)$ of the caregivers were in the upper social class. This could be a reflection of the ability of those in this group to afford the cost of accessing care at higher levels of health care delivery. However, there was no significant difference in the outcome of the cases, between the two main
TABLE 4: Health care option utilization and outcome in 33 children with cerebral malaria.

\begin{tabular}{lcccc}
\hline Health care option utilized & Total & Survived & Died & $P$ Value \\
\hline Health facility & 24 & 23 & 1 & 0.01 \\
PMS & 12 & 11 & 1 & 0.63 \\
Home treatment & 10 & 10 & 0 & 0.29 \\
Herbal concoction & 6 & 3 & 3 & 0.03 \\
\hline
\end{tabular}

social classes. The marginal difference could have been higher with a larger sample size.

Out of the health care options employed by the caregivers, the PMSs was the commonest first choice. The PMS belong to the informal health care sector and have been found to be routinely patronized by caregivers of sick children in the region of study and are often found selling, prescribing, and administering drugs for a variety of disease conditions [5]. They offer their services at an affordable cost making their use quite attractive. Since they have no formal pharmacological or medical training, their services could lead to grave consequences for patients.

Home treatment was another treatment option used by the caregivers. It was the second most preferred first choice health care option. The practice of home treatment of disease is equally common in the region. In studies conducted about the management of fever, acute lower respiratory tract infections, and diarrhea in the region, home treatment was used in $67.2 \%, 60.5 \%$, and $53.5 \%$ of the patients, respectively [6-8]. The allure for home treatment includes its apparent time saving feature and cheaper cost. However, it is often inadequate, and like in the case of the PMS could worsen morbidity and lead to delay in accessing appropriate health care. It is important to note that home management for malaria (HMM) has been identified as a useful tool in the reduction of morbidity and mortality resulting from malaria [5]. This initiative requires training of prospective operators, and this was lacking in the cases studied.

The use of herbal concoction in $6(18.2 \%)$ cases reflect to some degree the practice of the use of traditional medicine in tropical Africa where $70-80 \%$ of the populations patronize traditional healers [9]. The use of herbal mixtures is founded in the belief that herbs are efficacious in the management of diseases. In the south eastern Nigeria for example, Iloeje [10] observed that $28.3 \%$ of parents believe that the best treatment for febrile convulsion is traditional medicine. Furthermore, the ingredients are readily available and 
affordable, but unhygienic preparations and potentially harmful combinations coupled with unconventional prescriptions make the use of herbal concoctions hazardous. However, proper processing and application of herbal extracts seen with artemisinin from Artemisia annua and Quinine from cinchona alkaloids have been quite efficacious in the management of malaria [9]. It underscores the need for orthodox and nonorthodox health institutions to collaborate in the fight against endemic and potentially grave diseases.

Over $60 \%$ of the cases in this study made use of formal health facility as an initial choice of health care. However, its preference in this study was as second or third choice of health care signifying that though desirable, there were limitations to its use as a first choice health care option. Perception of disease, severity, cost of management, accessibility to care, and attitude of health workers are some of the factors that influence utilization of services of formal health facilities. Optimizing these factors would contribute to preventing delay in accessing definitive management.

\section{Conclusion}

Overall, most caregivers in the study utilized health care options, in a similar manner to that observed with other febrile illnesses $[6,7]$, which invariably exposed their respective wards to inappropriate and inadequate treatment. Consequently, effort should be focused on educating child caregivers particularly parents, on early recognition, and use of appropriate health care options for common illnesses. Furthermore, the role of other informal health services such as traditional medicine and PMS in child health care delivery should be appraised with a view to augmenting formal health services. These actions will equally foster achievement of the Millennium Development Goal of combating common childhood illnesses [11].

\section{Conflict of Interests}

The authors state that there were no competing interests in the study.

\section{References}

[1] S. A. Ogun, "Management of Malaria," Nigerian Medical Practitioner, vol. 49, no. 5, pp. 94-101, 2006.

[2] G. O. Ogunrinde, W. N. Ogala, and M. A. Bugage, "Cerebral Malaria in Zaria. A review of 50 cases. Abstracts of proceedings, 30th Annual General and Scientific conference of the Paediatric Association of Nigeria, Sokoto January 26-30, 1999," Nigerian Journal of Paediatrics, vol. 26, no. 2-4, p. 62, 1999.

[3] M. N. Jiya, K. I. Airede, and H. Ahmed, "Cerebral Malaria: presentation and outcome in children in Sokoto," Nigerian Medical Practitioner, vol. 50, no. 3-4, pp. 55-61, 2006.

[4] G. Oyedeji, "Socio-economic and cultural background of hospitalized children in Ilesha," Nigerian Medical Practitioner, vol. 12, pp. 111-117, 1985.

[5] R. M. Akuse, E. E. Eseigbe, A. Ahmed, and W. R. Brieger, "Patent medicine sellers: how can they help control childhood Malaria?" Malaria Research and Treatment, vol. 2010, Article ID 470754, 7 pages, 2010.
[6] L. I. Audu and W. N. Ogala, "Home treatment of children with fever in Zaria, Nigeria," Nigerian Medical Practitioner, vol. 34, pp. 17-19, 1997.

[7] I. S. Ighogboja, I. A. Angyo, and A. A. Okechukwu, "Clinical and epidemiological features of childhood acute lower respiratory infection (ALRI) in Jos," Nigerian Journal of Paediatrics, vol. 23, pp. 42-48, 1996.

[8] O. A. Babaniyi, B. J. Maciak, and Z. Wambai, "Management of diarrhoea at the household level: a population-based survey in Suleja, Nigeria," East African Medical Journal, vol. 71, no. 8, pp. 531-535, 1994.

[9] H. A. B. Coker and S. A. Adesegun, "The malaria scourge: The place of complementary traditional medicine," Nigerian Medical Practitioner, vol. 49, no. 5, pp. 126-132, 2006.

[10] S. O. Iloeje, "The impact of socio-cultural factors on febrile convulsions in Nigeria," West African Journal of Medicine, vol. 8, no. 1 , pp. 54-58, 1989.

[11] United Nations: The Millennium Development Goals Report 2008, BMJ 2008, http://www.un.org/millenniumgoals/. 


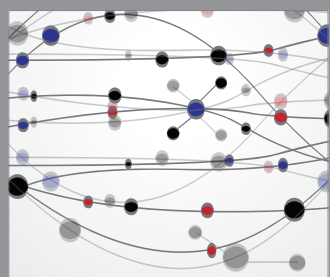

The Scientific World Journal
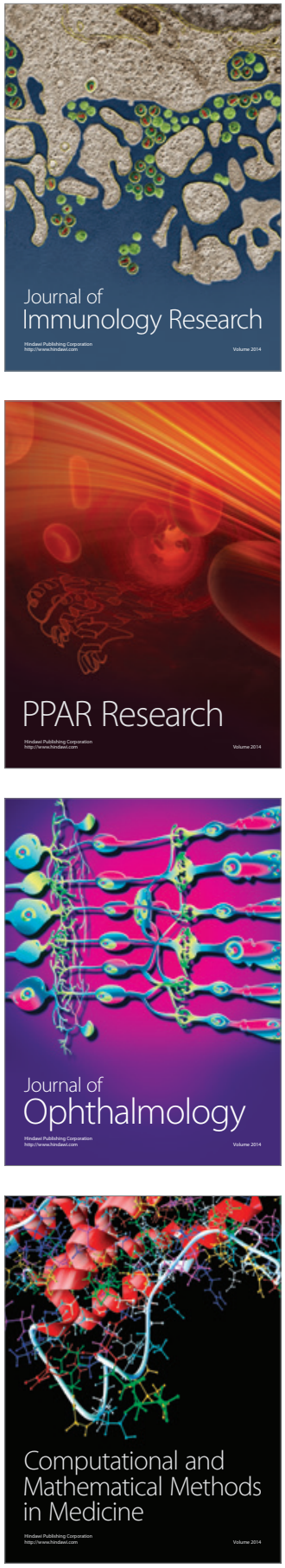

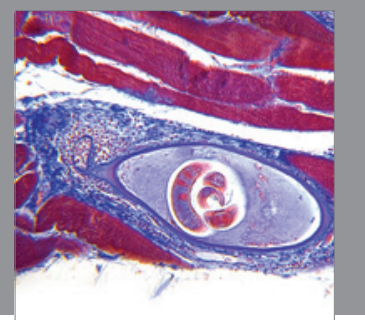

Gastroenterology

Research and Practice
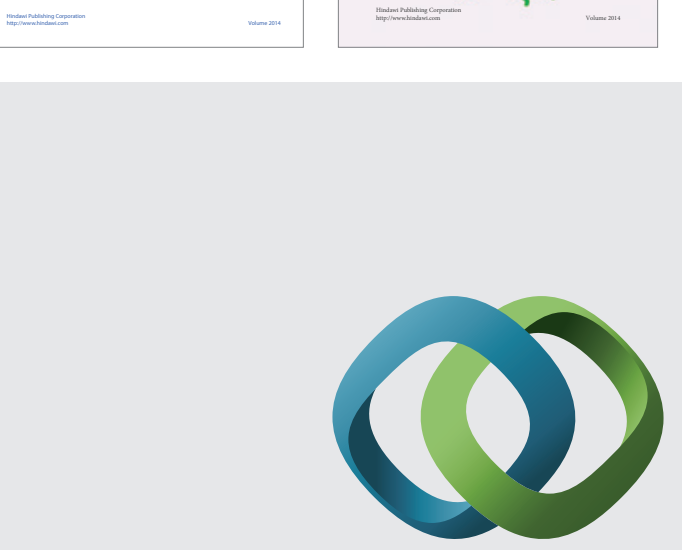

\section{Hindawi}

Submit your manuscripts at

http://www.hindawi.com
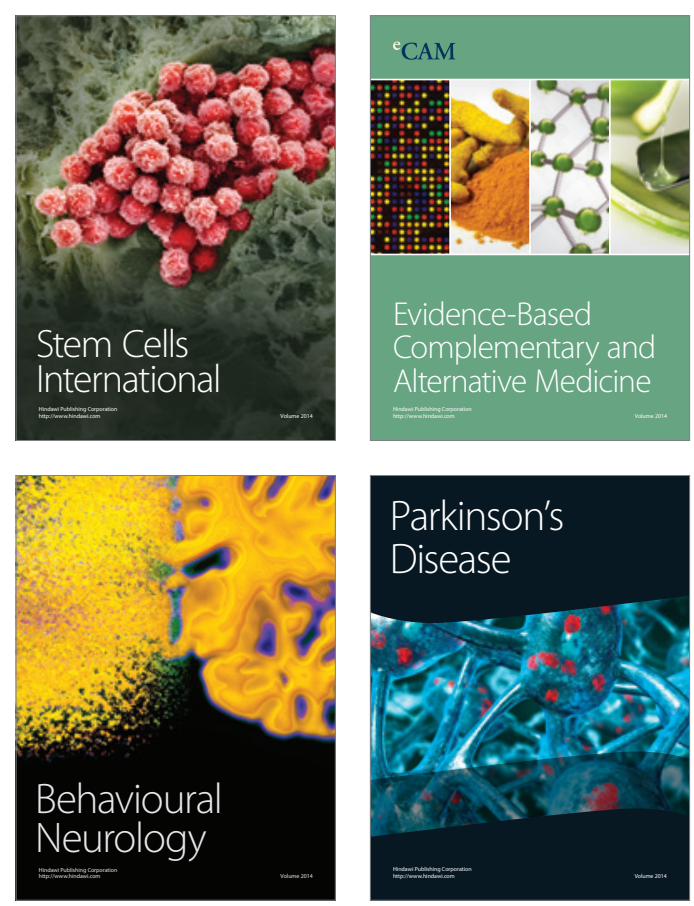

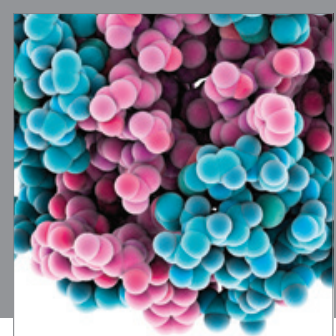

Journal of
Diabetes Research

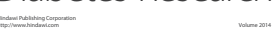

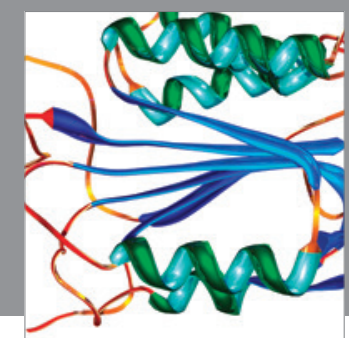

Disease Markers
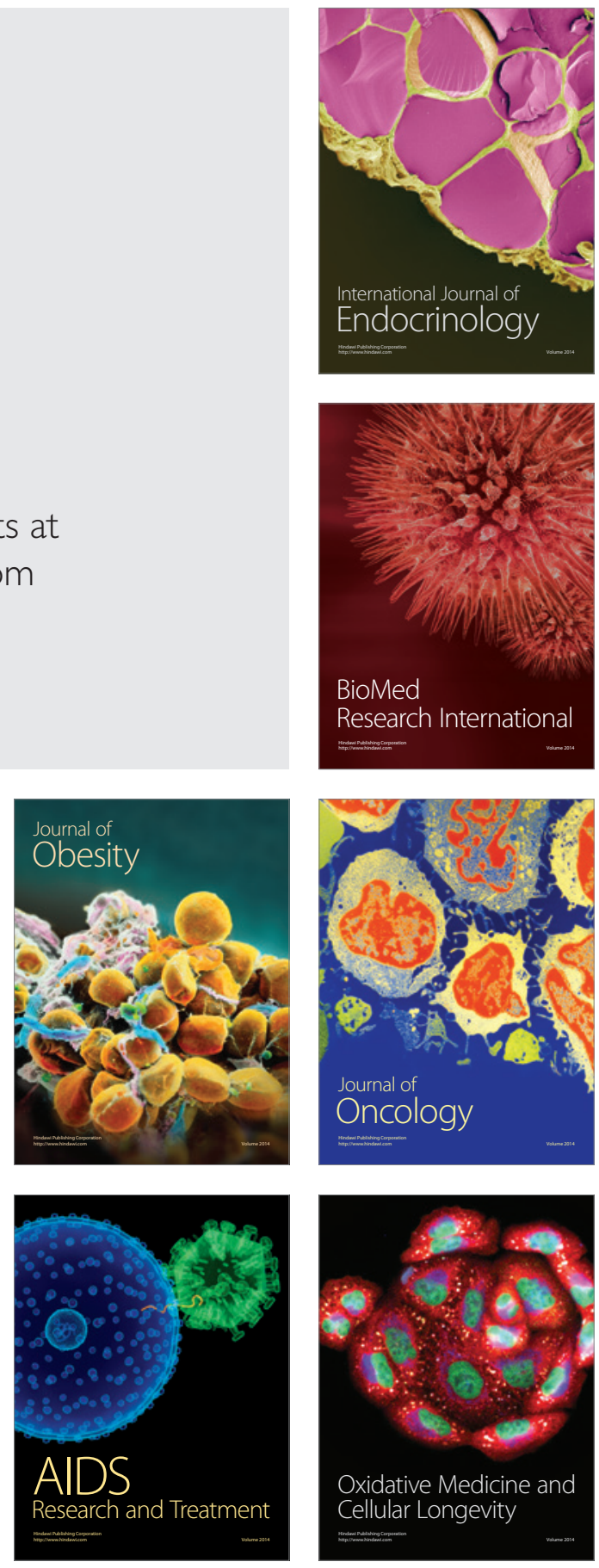